15

\title{
Анализ взаимосвязи процессов поляризации с микроструктурированием в слое магнитной жидкости
}

\author{
(C) Т.Ф. Морозова, М.С. Демин ॠ \\ Северо-Кавказский федеральный университет, \\ 355009 Ставрополь, Россия \\ ฯ e-mail: demin_ms@mail.ru
}

(Поступило в Редакцию 26 февраля 2016 г.)

\begin{abstract}
Приведены результаты исследований и анализ взаимосвязи процессов поляризации со структурированием в микрослоях магнитной жидкости при воздействии температуры, внешних электрического и магнитного полей, изменений структуры и количества стабилизатора.
\end{abstract}

DOI: 10.21883/JTF.2017.02.44140.1782

\section{Введение}

Известно, что поведение систем с углеводородной дисперсионной средой в электрических полях определяется сочетанием электрохимических и электрофизических явлений, где определяющую роль играют процессы диэлектрической поляризации, взаимосвязанные с электрокоагуляционным структурированием [1]. Микроструктурные образования и их трансформации, влияя на макроскопические свойства дисперсных систем, являются основой для регулирования процессов получения материалов с заданными свойствами, поэтому в $[2,3]$ указывалось на актуальность изучения возможности управления электрофизическими характеристиками микрослоев магнитных жидкостей (МЖ), воздействуя на их структуру внешними полями.

Рассматриваемые высокодисперсные коллоиды ферромагнетиков - МЖ представляют собой матричные смеси, где матрица - диэлектрик: неполярная углеводородная среда, содержащая свободные полярные молекулы олеиновой кислоты, и включения - проводящие нанодисперсные частицы магнетита, покрытые защитным слоем стабилизатора: олеиновой или стеариновой кислотами. Поэтому при анализе поляризационных процессов, происходящих в магнитных жидкостях, не исключается возможность применения формул Оделевского и Брюггемана, а также обобщенной формулы Клаузиса-Мосотти (Ланжевена-Дебая), связывающей диэлектрическую проницаемость с поляризуемостью составляющих его молекул, рассматриваемые в [4].

Вопросы поляризации магнитных частиц и связанные с ними процессы структурирования рассматривались во многих работах [5-9], но для „классических“ МЖ на основе керосина, стабилизированных олеиновой кислотой. Магнитные жидкости на вязких средах существенно отличаются от жидкостей на основе керосина, а отсутствие исследований влияния различных типов микроструктурных образований на диэлектрические свойства жидкостей ставит дополнительные задачи изучения МЖ с различной дисперсионной средой и дисперсной фазой, структурой и количеством стабилизатора.
Проведенные ранее эксперименты $[10,11]$ свидетельствуют, что подача постоянного поляризующего напряжения на микрослой МЖ приводит к нелинейному изменению электроемкости с выраженным максимумом, в котором фиксируется устойчивое структурирование его приэлектродных областей [9]. Области напряженности электрического поля, определяющие данное состояние микрослоя, зависят от концентрации твердой фазы, толщины слоя и температуры $[9,12]$. Анализ взаимосвязи эффективной диэлектрической проницаемости с процессами структурирования, проведенный в работах $[13,14]$, показал, что при малых напряженностях электрического поля в приэлектродных слоях формируется гетерозаряд и начинается процесс структурирования. При критических (пороговых) напряжениях, обусловливающих максимум диэлектрической проницаемости, под слоем гетерозаряда образуется гомозаряд, а возникающее при этом структурное состояние микрослоя является практически устойчивым. Относительная роль гетерои гомозарядов в формировании структурного состояния зависит от геометрии эксперимента, температуры, величины напряженности электрического поля и физических свойств границы „электрод-диэлектрик“ $[15]$. Дальнейший рост электрического поля увеличивает плотность гомозаряда за счет контактных явлений на границе „электрод-жидкость“, и состояние микрослоя приобретает гидродинамическую неустойчивость в виде конвективных ячеек. Таким образом, переход из устойчивого состояния микрослоя МЖ в неустойчивое происходит при напряженностях электрического поля, бо́льших некоторой критической величины, когда периодическая структура претерпевает распад.

Таким образом, многочисленные исследования микрослоев магнитных жидкостей свидетельствуют о возникновении под воздействием температуры, внешних электрических и магнитных полей, пространственных структурных образований, вид которых определяется характером и степенью взаимной ориентации молекул дисперсионной среды и магнитных наночастиц, т.е. процессами поляризации [8]. В работе [4] установлено, что поляризация в магнитной жидкости является 
совокупностью ионной и ориентационной поляризаций, неоднозначно зависящих от теплового движения, но преимущественно тепловой ориентационной поляризацией. Увеличение вязкости МЖ за счет дополнительного введения стабилизатора и смены дисперсионной среды [16] также способствуют появлению более упорядоченных структур в приэлектродных слоях ячейки, заполненной магнитной наножидкостью.

Известно, что диэлектрическая поляризация всех видов не устанавливается мгновенно. Поляризация, обусловленная тепловым движением, протекает медленнее, чем поляризация смещения под воздействием электрического поля. Состояние любой макроскопической системы определяется большим числом параметров, при этом установление равновесия по каждому из них протекает различно и количественно характеризуется временем релаксации, которое необходимо определять как время, в течение которого электрический момент единицы объема уменьшается в $e$ раз после снятия внешнего поля [17].

Целью настоящего исследования является анализ поляризационных процессов, происходящих в микрослоях МЖ при воздействии температуры и внешних электрического и магнитного полей, а также установление корреляции времен формирования структурированного состояния среды (времен релаксации) с процессами поляризации в магнитной жидкости с различной структурой и количеством стабилизатора, находящихся под воздействием внешнего электрического поля.

\section{Результаты и анализ проведенных экспериментов}

Результаты экспериментов, являющиеся объектом анализа, получены из $[4,5,9,11-16]$ для микрослоев магнитной жидкости 50-100 $\mu \mathrm{m}$, которые создавались между двумя плоскопараллельными электродами с размерами $40 \times 50 \mathrm{~mm}^{2}-$ стеклянными пластинами с проводящей поверхностью, создаваемой напылением $\mathrm{In}_{2} \mathrm{O}_{3}-\mathrm{SnO}_{2}$ толщиной до $0.4 \mu \mathrm{m}$ или стальными пластинами, т.е. микроконденсатора, заполненного наножидкостью. Микроскопические наблюдения микрослоя МЖ в оптический микроскоп и фотографирование структурного состояния его приэлектродных слоев производились одновременно с измерением величин электроемкости и электропроводности на частоте $1 \mathrm{kHz}$ с подачей постоянного поляризующего напряжения до $20 \mathrm{~V}$ измерителем типа E7-8 в интервале температур $20-100^{\circ} \mathrm{C}$. Прибор Е7-8 измеряет характеристики конденсаторов в виде компонентов параллельной схемы замещения, что на частоте $1 \mathrm{kHz}$ соответствует физической структуре конденсатора. Амплитудное значение напряжения на измеряемом объекте не превышало $4.3 \mathrm{~V}$, а величина поляризующего напряжения изменялась в диапазоне 0.5-20 V. Однородное магнитное поле $H=30 \mathrm{kA} / \mathrm{m}$ создавалось катушками Гельмгольца и направлялось параллельно электрическому. Погрешность измерений не превышала $1.2 \%$. Наблюдения в проходящем свете дали возможность проследить динамику образования, трансформацию и распад приэлектродных структур микрослоя магнитной жидкости.

Анализ проведенных экспериментальных исследований и аналитических расчетов показал, что релаксация структурированного микрослоя магнитной жидкости, находящегося под воздействием поляризующего напряжения, в зависимости от концентрации твердой фазы происходит практически по экспоненциальному закону в соответствии с уравнением Аррениуса. При этом зависимости $\tau=f\left(U_{p}\right)$ в исследуемом концентрационном диапазоне $2-14 \%$ неоднозначны (рис. 1). Ранее в работах $[9,13,14]$ МЖ с объемной концентрацией $6 \%$ твердой фазы - магнетита в дисперсионной среде „керосин“ - определена как концентрация с наиболее
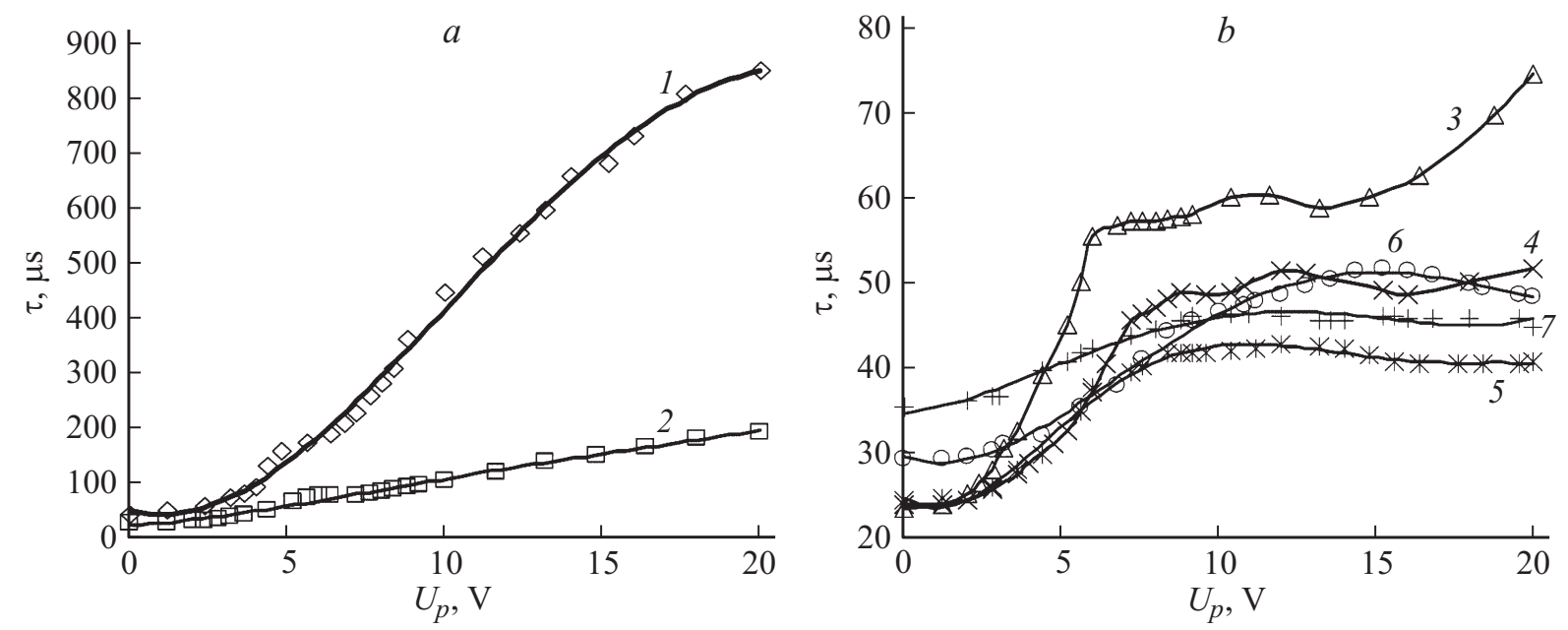

Рис. 1. Зависимости $\tau=f\left(U_{p}\right)$ для магнитной жидкости с концентрациями твердой фазы, \%: $1-2.3,2-4.3,3-6.3,4-8.3$, $5-10.3,6-12.3,7-14.3$. 


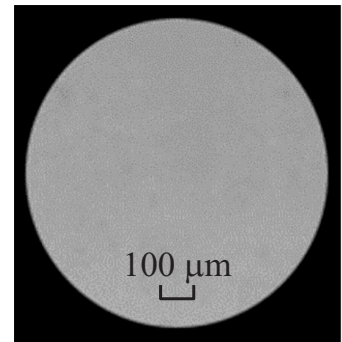

$1 a$

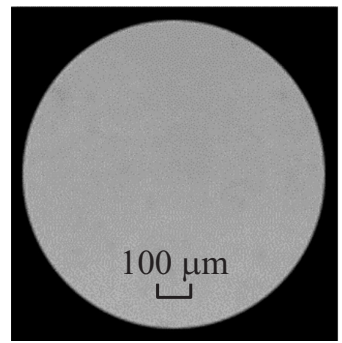

$1 b$

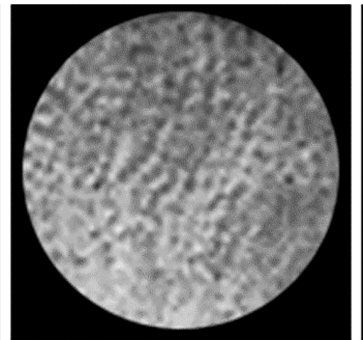

$2 a$

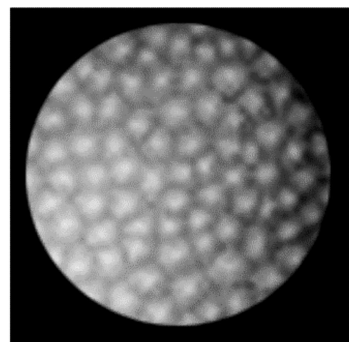

$2 b$

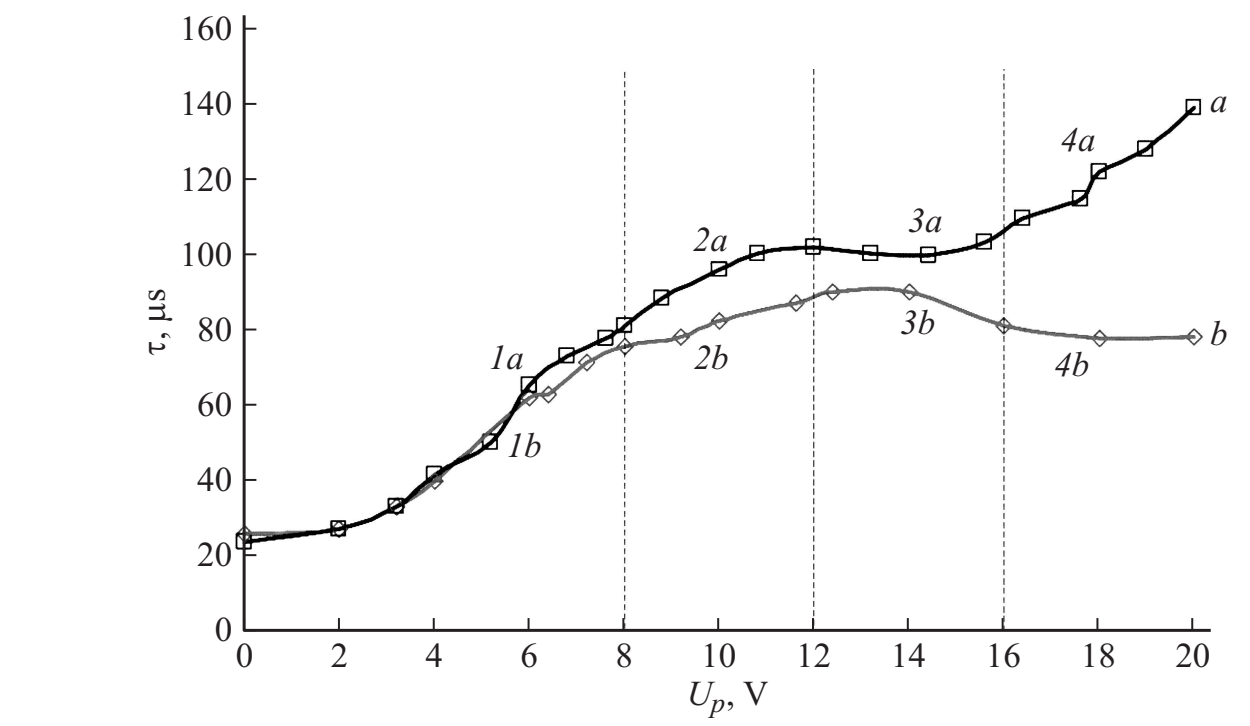

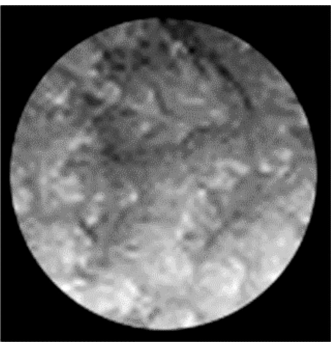

$3 a$

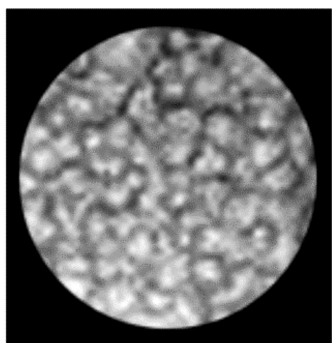

$3 b$

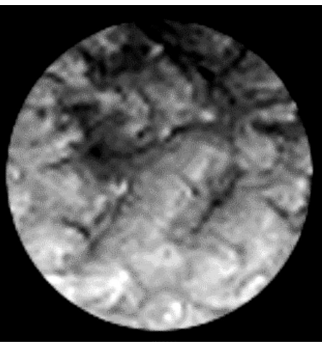

$4 a$

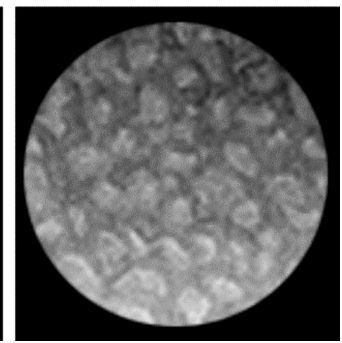

$4 b$

Рис. 2. Сравнительная характеристика $\tau=f\left(U_{p}\right)$ и последовательные стадии развития структурных изменений в микрослое $(d=50 \mu \mathrm{m})$ МЖ с концентрацией твердой фазы: $a-6.3 \%$, тип „магнетит в керосине“; $b-6.3 \%$ с избытком олеиновой кислоты (1\% к объему).

ярко выраженными процессами структурирования и поляризации. Полученные зависимости времен релаксации в работе [18] также указывают на особое положение МЖ данной концентрации, где для нее на кривой $\tau=f\left(U_{p}\right)$ выделено три характерных участка:

а) первый участок свидетельствует о начальной стадии формирования слабопроводящих приэлектродных областей, т.е. о расслоении однородного микрослоя жидкости на приэлектродные и объемную области, на котором наблюдается монотонное возрастание $\tau$,

б) второй - о полностью сформированных приэлектродных областях с устойчивыми структурными образованиями, где электрическое поле преимущественно сосредоточено в данных областях, и величина $\tau$ практически неизменна, в) третий - о развитых электрогидродинамических (ЭГД) течениях, приводящих к разрушению приэлектродных структурных областей, где электрическое поле распределено в объеме межэлектродного пространства макроскопически более равномерно.

Для магнитных жидкостей с концентрацией 8-10\% процессы формирования приэлектродных слоев аналогичны рассмотренной 6\%-ной жидкости; разрушений в микрослое с концентрацией $12-14 \%$ твердой фазы под воздействием ЭГД-течений в силу большей вязкости и структурного сопротивления магнитной жидкости практически не наблюдается. В микрослоях магнитной жидкости с малыми концентрациями 2-4\% твердой фазы в исследуемом диапазоне изменения электрического поля 0-20 V устойчивых приэлектродных структурообразова- 


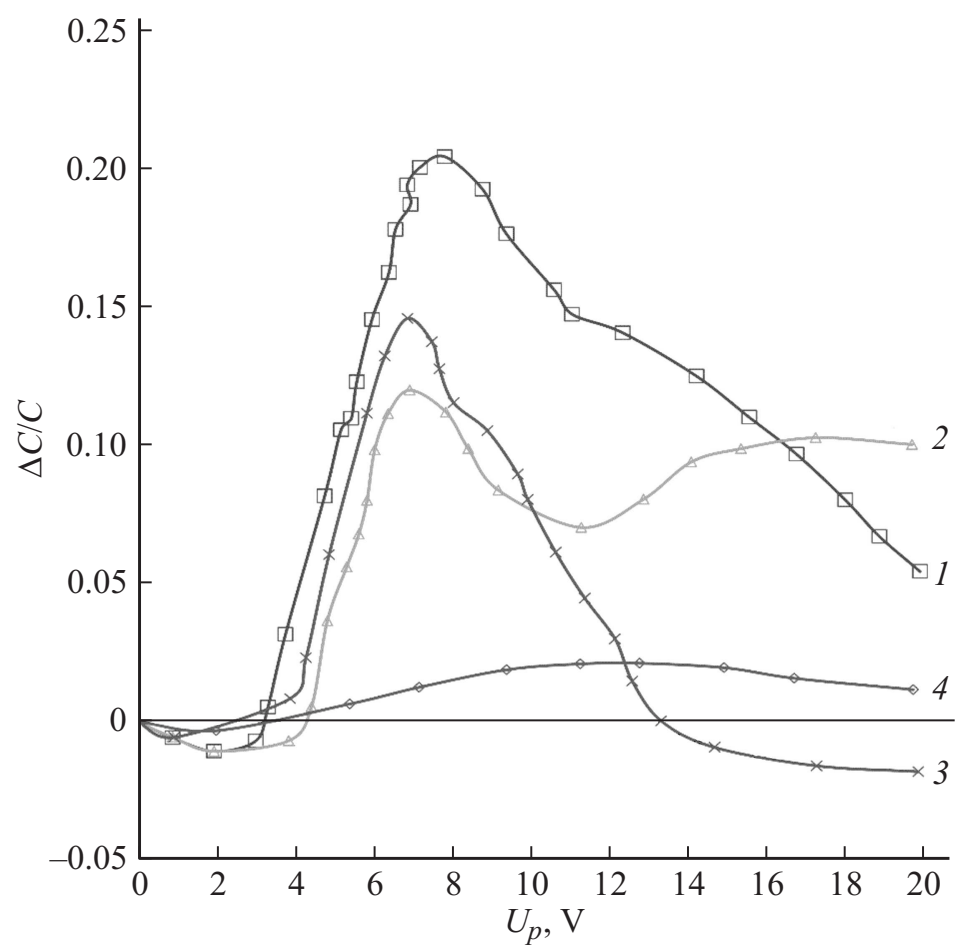

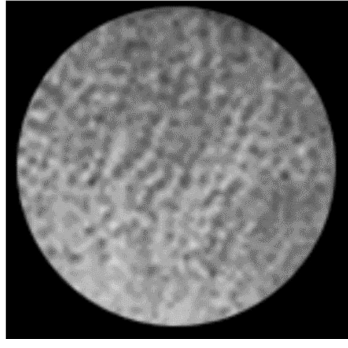

1

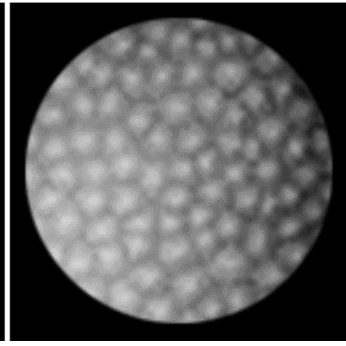

2

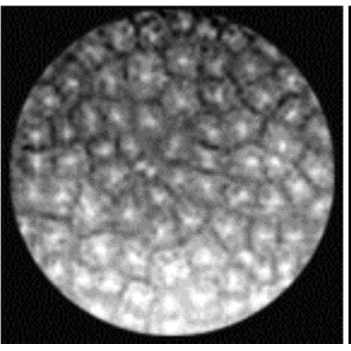

3

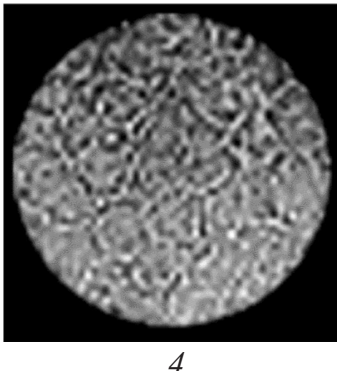

4

Рис. 3. Зависимости $\Delta C / C=f\left(U_{p}\right)$ и структурное состояние микрослоя МЖ $50 \mu \mathrm{m}$ с концентрацией твердой фазы $6 \%$ в максимуме электроемкости для жидкостей: $1-$ „магнетит в керосин““, $2-$ „магнетит в керосине $+1 \%$ свободной олеиновой кислоты к объему“, 3 - „магнетит в керосине (ПАВ: стеариновая и олеиновая кислоты)“, 4 - „магнетит в трансформаторном масле“.

ний не наблюдается из-за постоянного разрушения их ЭГД-течениями.

Образование новой, более концентрированной фазы в первоначально однородной МЖ при воздействии постоянного электрического поля $[19,20]$ может быть интерпретировано на основе представлений об устойчивости коллоидов. При этом получение устойчивого коллоида связано с выбором стабилизатора (поверхностноактивного вещества - ПАВ), оптимизацией соотношения между его компонентами, переводом дисперсной фазы из одного типа дисперсионной среды в другой [21]. В работе [16] показано, что увеличение свободной олеиновой кислоты до $1 \%$ к объему „классической“ магнитной жидкости при прочих равных условиях эксперимента обусловливает циркуляцию приэлектродных областей микрослоя в виде „ячеек Бенара“, границы которых состоят из магнитных частиц. Сравнительные характеристики времен релаксации $\tau=f\left(U_{p}\right)$ иссле- дуемой $6.3 \%$-ной жидкости и с избытком свободной олеиновой кислоты приведены на рис. 2.

Указанные расчетные зависимости и результаты микроскопических наблюдений приэлектродных областей микрослоя магнитной жидкости показывают, что увеличение вязкости за счет дополнительного введения стабилизатора приводит к уменьшению времени формирования и упорядочению их структурного состояния (рис. 2, кривая $b$ ).

Результаты расчета времен релаксации микрослоев магнитной жидкости всего исследуемого концентрационного диапазона $2-14 \%$ в функции от изменений температуры $20-100^{\circ} \mathrm{C}$ в отсутствие электрического поля показали снижение времени релаксации с увеличением температуры [17] практически по экспоненциальному закону. Дополнительное воздействие температуры на микрослой магнитной жидкости, находящейся в поляризующем напряжении, величина которого определяет его 

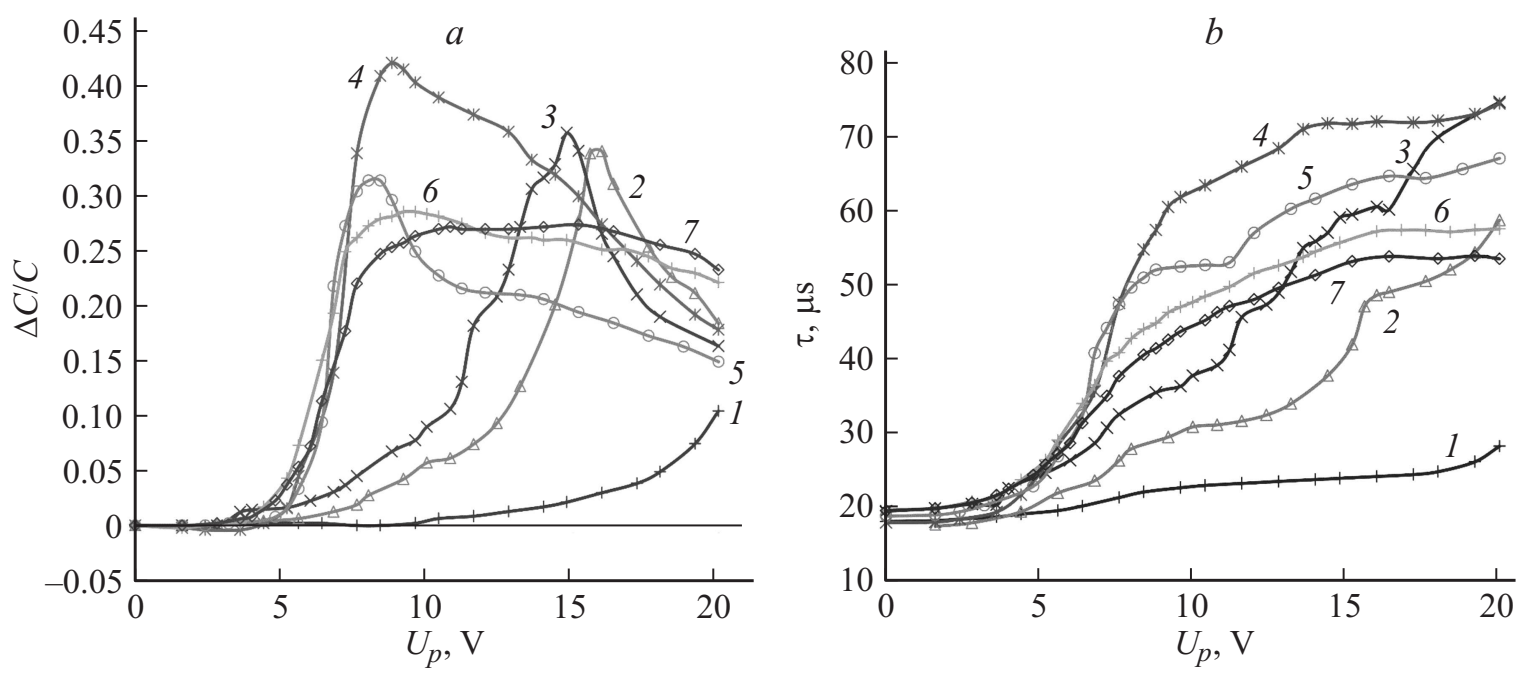

Рис. 4. Зависимости $\Delta C / C=f\left(U_{p}\right)$ и $\tau=f\left(U_{p}\right)$ микрослоя с МЖ 9.5\% системы электродов сталь-сталь от концентрации свободной олеиновой кислоты при воздействии постоянного электрического поля: 1 - исходная жидкость без свободной олеиновой кислоты, $2-1,3-2,4-4,5-6,6-8,7-10 \%$.

наибольшую поляризацию, снижает время релаксации, так как увеличение температуры способствует возрастанию подвижности ионов и магнитных наночастиц.

Как указано выше, в микрослое МЖ с объемной концентрацией магнетита $6 \%$ в дисперсионной среде „керосин“ наиболее ярко выражены процессы структурирования, отмечено значительное (по отношению к диапазону концентраций МЖ 2-14\%) превышение $\varepsilon=f\left(U_{p}\right)$ в ее максимуме, т.е. наибольшая поляризация. Поэтому в дальнейшем микроскопические наблюдения процесса устойчивого структурирования приэлектродных областей микрослоев МЖ проводились с соблюдением концентрации твердой фазы в 6\% и межэлектродного промежутка $d=50-100 \mu \mathrm{m}$.

Смена дисперсионной среды в магнитной наножидкости указывает на качественно-различный характер изменения электроемкости, что подтверждается результатами исследования жидкостей, приготовленных на основе трансформаторного масла и полиметилсилоксана [16]. При этом максимальная величина относительного изменения электроемкости $\Delta C / C=f\left(U_{p}\right)$ ячейки при межэлектродном расстоянии $50 \mu \mathrm{m}$ для наножидкости „магнетит в трансформаторном масле“ и „магнетит в полиметилсилоксане“ с равной объемной концентрацией твердой фазы в 6\% снижается на порядок по отношению к аналогичной ячейке с наножидкостью „магнетит в керосине“. Микроскопические наблюдения приповерхностного слоя МЖ „магнетит в трансформаторном масле“ указывают на образование лабиринтной структуры, возникающей в максимуме электроемкости, в то время как для „классической“ МЖ в аналогичных условиях структуры „веретенообразные“ (рис. 3).

Как отмечено в работе [22], вопрос о влиянии избытка стабилизатора на структуру магнитных жидкостей остается дискуссионным, но проведенные авторами исследования показали, что на стадии получения нанодисперсных частиц магнетита небольшое избыточное количество стабилизатора следует считать необходимым технологическим приемом, гарантирующим защитный слой на частицах.

Изменение количества стабилизатора в „классической“ МЖ показало, что избыток свободной олеиновой кислоты (ПАВ) снижает максимальную величину электроемкости вдвое в указанных выше областях напряженности электрического поля [16]. При этом движение жидкости в приэлектродном слое указывает на возникновение структур, подобных „ячейкам Бенара“, границы которых состоят из магнитных частиц (рис. 3, кривая 2). Известно, что свойства коллоидных систем зависят от типа и структуры стабилизатора, поэтому были проведены наблюдения приповерхностного структурирования микрослоя МЖ также и при изменении структуры стабилизатора: сочетание олеиновой и стеариновой кислот, которые обусловили более четкую циркуляцию в виде „ячеек Бенара“. При этом на нелинейной зависимости $\Delta C / C=f\left(U_{p}\right)$ максимум электроемкости приобретает резко выраженный характер в том же диапазоне напряженности электрического поля, но с величиной, в 1.5 раза меньшей по отношению к МЖ, стабилизированной только олеиновой кислотой (рис. 3, кривая 3). Аналогичные структуры наблюдались в [23] для МЖ с микрокапельной структурой. Возможно, такая циркуляция поддерживает первопричину ее возникновения неравномерную плотность гетерозаряда - благодаря притоку к электроду разноименно заряженной жидкости и оттоку перезарядившейся жидкости.

Приведенные выше результаты микроскопических наблюдений структурных состояний микрослоя МЖ (рис. 3) показали $[9,16]$, что увеличение вязкости МЖ за счет изменения дисперсионной среды, дополнитель- 


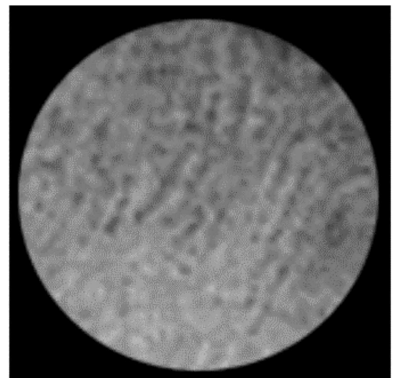

$a$

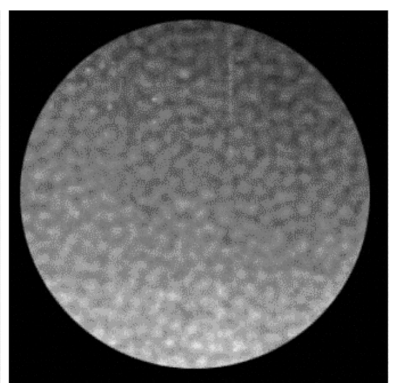

$b$

$$
E=200 \mathrm{kV} / \mathrm{m}
$$

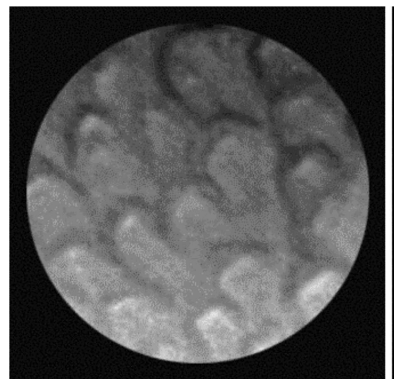

$a$

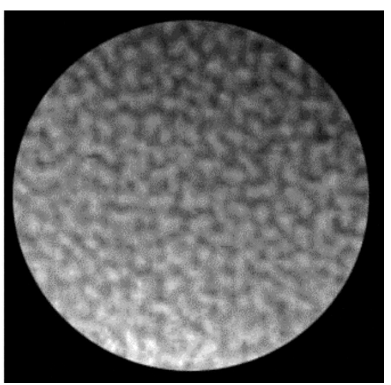

$b$

$$
E=240 \mathrm{kV} / \mathrm{m}
$$

Рис. 5. Структурирование микрослоя „классической“ МЖ (магнетит в керосине) с концентрацией твердой фазы 6\%: $a-$ электрическое поле, $b$ - электрическое и магнитное поля.

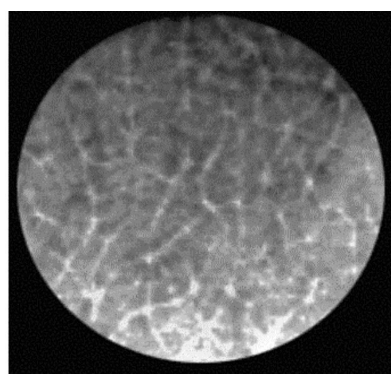

$a$

$$
E=200 \mathrm{kV} / \mathrm{m}
$$

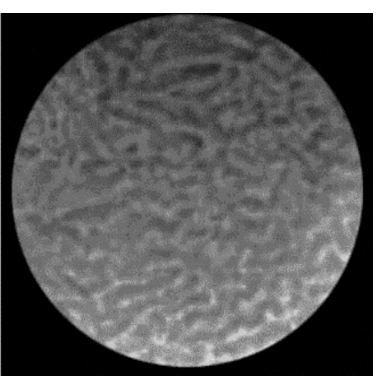

$b$

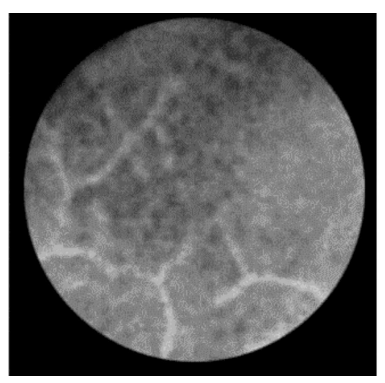

$a$

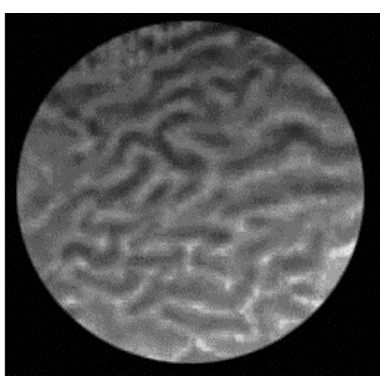

$b$

$$
E=340 \mathrm{kV} / \mathrm{m}
$$

Рис. 6. Структурирование микрослоя „классической“ МЖ (магнетит в керосине) с концентрацией твердой фазы 6\% и избытком ПАВ 1\% к объему: $a$ - электрическое поле, $b$ - электрическое и магнитное поля.

ного введения стабилизатора приводит к упорядочению устойчивых микроструктурных образований. Для выявления оптимального количества свободного ПАВ, необходимого для получения упорядоченного структурного состояния в микрослое МЖ, исследовались жидкости, полученные методом повторной пептизации из промышленных ферроколлоидов. Это позволило „очистить“ жидкость от свободного ПАВ и немагнитных примесей, что подтверждено исследованиями магнитной динамической восприимчивости, которая на 20\% больше, чем

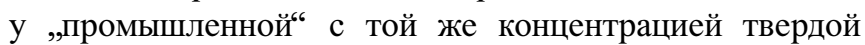
фазы в 9.5\%. В результате добавления в „очищенную“ МЖ фиксированных концентраций олеиновой кислоты (от 1 до 10\% к объему) установлено, что присутствие свободной ПАВ проявляется в том, что на нелинейной зависимости $\Delta C / C=f\left(U_{p}\right)$ возникает максимум, отсутствующий в „очищенной“ МЖ [24]. Выраженный максимум электроемкости характерен для диапазона концентраций стабилизатора $1-6 \%$, а его наибольшее значение соответствует концентрации в $4 \%$ в области напряженности $E=80-100 \mathrm{kV} / \mathrm{m}$, но с дальнейшим увеличением концентрации свободной олеиновой кислоты он сглаживается (рис. 2, $b$ ).

Таким образом, в данном эксперименте определена оптимальная объемная концентрация свободной олеино- вой кислоты в $4 \%$, которая при величине электрического поля $E=80 \mathrm{kV} / \mathrm{m}$, определяет максимальную поляризацию микрослоя с высокой степенью упорядоченности ее приповерхностных структур, что подтверждает взаимосвязь процесса структурирования микрослоя МЖ от ее электропроводности $[16,17]$ и согласуется с результатами, полученными в [25]. Аналогия же вида зависимостей электроемкости при воздействии поляризующего напряжения в оптически прозрачных и непрозрачных электродах предполагает подобные структурные видоизменения в различных электродных системах [15].

Полученные же зависимости времен релаксации для данных экспериментальных исследований по выявлению оптимального количества свободного ПАВ указывают, что только при объемной концентрации свободной олеиновой кислоты в 6\% можно говорить о длительном устойчивом состоянии микрослоя, когда время релаксации меньше, чем для концентрации в 4\% с большей поляризацией в микрослое, и не изменяется в большем диапазоне напряженности поля (рис. 4, $b$, кривые 1 и 2). По аналогии с ранее приведенными исследованиями на кривой зависимости $\tau=f\left(U_{p}\right)$ также можно выделить три характерных участка: расслоение однородного микрослоя жидкости на приэлектродные и объемную области; формирование приэлектродных областей с 
устойчивыми структурными образованиями; разрушение приэлектродных структурных областей. Таким образом, можно полагать о значительном вкладе стабилизатора в формировании устойчивых микроструктурных образований в сложной многокомпонентной магнитной наножидкости.

Но если электрическое поле определяет устойчивость структуры в узком диапазоне его изменения, то дополнительное воздействие магнитного поля расширяет диапазон устойчивости и степень упорядоченности структуры [16]. Так, для микрослоя МЖ „магнетит в керосине“, наблюдаемая „веретенообразная“ структура в максимуме электроемкости трансформируется в „зернистую“ под дополнительным воздействием магнитного поля (рис. 5). С увеличением напряженности электрического поля „чешуйчатая“ структура преобразуется в устойчивую „лабиринтную“ в магнитном поле. Для микрослоя МЖ с избытком олеиновой кислоты $1 \%$ к объему также наблюдается возрастание степени упорядоченности под действием магнитного поля (рис. 6).

Образование пространственных структур под воздействием внешних электрических и магнитных полей определяется характером и степенью взаимной ориентации молекул дисперсионной среды и магнитных частиц, т.е. процессами поляризации, поэтому в [4] отмечено, что поляризация МЖ, возникающая под действием электрического поля, является совокупностью ионной и ориентационной поляризаций. Предполагается, что дополнительное введение стабилизатора и смена „классической“ дисперсионной среды на более вязкую, способствующие упорядочению микроструктурных образований, уменьшая активный объем дисперсионной среды микрослоя, снижают ионную составляющую процесса поляризации МЖ. В этом случае можно предполагать, что в состоянии структурного упорядочения поведение МЖ аналогично магнитно-реологической суспензии [21].

\section{Заключение}

Так как значения времен релаксации определяются свойствами и структурным состоянием системы и зависят от внешних условий, для рассматриваемых микрослоев магнитной жидкости в соответствии с [17], можно полагать, чем больше время релаксации, тем медленнее протекает нестационарный процесс - зарождение структурных образований. Вид структурных образований определяется концентрацией твердой фазы, свойствами дисперсионной среды, количеством и структурой стабилизатора, толщиной микрослоя магнитной жидкости, внешними электрическими и магнитными полями, температурой среды и материалом электродов [9,11-16]. Состояние равновесия по каждому из этих параметров определяет практически неизменную величину времени релаксации, которая соответствует времени установления термодинамического равновесия - формирования пространственных устойчивых микроструктурных об- разований приэлектродных областей, соответствующих наибольшей поляризации в микрослое магнитной наножидкости.

Из проведенных исследований можно сделать выводы, что для получения необходимой управляемой электрокоагуляционной структуры микрослоя МЖ следует к полученным в $[2,5,9,16,26,27]$ корреляциям между величиной напряженности электрического поля, концентрацией твердой фазы, толщиной микрослоя, температурной средой ввести дополнительные зависимости от структурного состава и количества стабилизатора, а также типа дисперсионной среды, что требует дальнейших исследований в этом направлении. При этом предполагается, что для сохранения пространственновременных микроструктур, обусловленных процессами поляризации, применим метод ,замораживания“ структуры, нашедший отражение в работе [4].

\section{Список литературы}

[1] Дейнега Ю.Ф., Ковганич Н.Я., Попко К.К. // Электронная обработка материалов. 1979. № 1. С. 38-42.

[2] Кожсевников В.М., Ларионов Ю.А., Морозова Т.Ф. // 9-я Междунар. Плесская конф. по магнитным жидкостям. 2000. C. $169-174$

[3] Кожевников В.М., Морозова Т.Ф., Аверьянов П.В. // Матер. Междунар. конф. „Химия твердого тела и современные микро- и нанотехнологии“. 2002. С. 260-261.

[4] Морозова Т.Ф. // Вестник СевКавГТУ. 2010. № 2 (23). C. $45-50$.

[5] Аверьянов П.В., Кожсевников В.М., Морозова Т.Ф. // Сб. науч. трудов 10-й Междунар. Плесской конф. по магнитным жидкостям. 2002. С. 187-193.

[6] Диканский Ю.И., Нечаева О.А. // Коллоидный журнал. 2003. T. 65. № 3. С. 338-342.

[7] Кожевников В.М., Чуенкова И.Ю., Данилов М.И., Ястребов С.С. // ЖТФ. 2000. Т. 76. Вып. 7. С. 129-131.

[8] Дюповкин Н.И. // Сб. науч. трудов 7-й Международной Плесской конф. по магнитным жидкостям. 1996. С. 42.

[9] Kozhevnikov V.M., Morozova T.F. // Magnetohydrodynamics. 2001. Vol. 37. N 4. P. 383-388.

[10] Кожевников В.М., Ларионов Ю.А., Падалка В.В., Бутенко A.A. // Тринадцатое Рижское совещание по магнитной гидродинамике. 1990. С. 89-90.

[11] Кожевников В.М., Морозова Т.Ф. // Сб. науч. тр. СевКавГТУ. Сер. „Физико-химическая“. 1999. Вып. 3. C. $60-66$.

[12] Аверьянов П.В., Кожсевников В.М., Морозова Т.Ф. // Сб. науч. тр. 1-й Российской науч.-практ. конф. „Физикотехнические проблемы создания новых технологий в агропромышленном комплексе“. Т. 2. 2001. С. 294-296.

[13] Морозова Т.Ф. Формирование структуры в магнитной жидкости при воздействии поляризующего напряжения. Дис. канд. физ.-мат. наук. Ставрополь: СевКавГТУ, 2002. $229 \mathrm{c}$.

[14] Аверьянов П.В., Кожевников В.М., Морозова Т.Ф. // Сб. науч. тр. 10-й Междунар. Плесской конф. по магнитным жидкостям. 2002. С. 187-193. 
[15] Аверьянов П.В., Кожсевников В.М., Морозова Т.Ф. // Известия вузов. Северо-Кавказский регион. Техн. науки. 2004. № 1. C. 49-54.

[16] Морозова Т.Ф., Демин М.С. // Вестник СевКавГТУ. 2012. № 1 (30). С. 35-40.

[17] Сканави Г.И. Физика диэлектриков. М.-Л.: ГИТТЛ, 1949. $810 \mathrm{c}$.

[18] Морозова Т.Ф., Демин М.С. // Вестник СевКавГТУ. 2012. № 3 (32). C. 9-12.

[19] Чеканов В.В., Бондаренко Е.А., Дискаева Е.Н. // Вестник Ставропольского гос. ун-та. 2005. Вып. 43. С. 85-92.

[20] Кожкевников В.М., Ларионов Ю.А., Чуенкова И.Ю., Морозова T.Ф. // Матер. 15-й Междунар. Плесской научной конференции по нанодисперсным магнитным жидкостям. 2012. С. $99-103$.

[21] Байбуртский Ф.С. Магнитные жидкости: способы получения и области применения. URL: http://magneticliquid.narod.ru

[22] Лисин А.В., Грабовский Ю.П. // Матер. III Всерос. научн. конф. Физико-химические и прикладные проблемы магнитных дисперсных наносистем. 2011. С. 240-245.

[23] Диканский Ю.И. Эффекты взаимодействия частиц и структурно-кинетические процессы в магнитных коллоидах. Дис. д-ра техн. наук. Ставрополь: СГУ, 1999. 305 с.

[24] Ларионов Ю.А., Чуенкова И.Ю., Морозова Т.Ф. // Матер. XXX науч.-техн. конф. 2000. С. 39.

[25] Диканский Ю.И., Вегера Ж.Г., Закинян Р.Г., Нечаева О.А., Гладких Д.В. // 11-я Междунар. Плесская конф. по магнитным жидкостям. 2004. С. 14-21.

[26] Кожевников В.М., Морозова Т.Ф., Филиппов С.А. // Сб. науч. тр. СтГТУ. Сер. Естественно-научная. 1999. Вып. 2. C. 104-107.

[27] Морозова Т.Ф., Демин М.С. // Матер. 41-й науч.-техн. конф. СевКавГТУ. 2012. Т. 1. С. 8-9. 